Paulina Pietraszak

Karolina Piaśnik

Koło Naukowe Studentów

Informacji Naukowej i Bibliotekoznawstwa

Uniwersytet Jagielloński

\title{
Strona www biblioteki akademickiej jako narzędzie PR
}

Public relations $(\mathrm{PR})$ określa się jako komunikację polegającą na przekazywaniu informacji i prowadzeniu dialogu pomiędzy organizacją a jej publicznością w celu budowania i utrzymywania w odbiorze pozytywnego wizerunku organizacji ${ }^{1}$. Co ważne, jest to działalność ciagła, planowa i prowadzona $z$ uwzględnieniem wyników systematycznych badań. Obecnie coraz częściej bibliotekarze zdają sobie sprawę z konieczności podjęcia działań public relations i przeznaczają na nie środki finansowe, nierzadko rezygnując np. z powiększenia księgozbioru. Podstawowym celem public relations w każdej organizacji czy instytucji jest zadowolenie klienta, czyli zaspokojenie oczekiwań użytkowników. Aby to osiagnąć, niezbędne jest budowanie pozytywnego wizerunku danej instytucji w środowisku potencjalnych odbiorców i współpracowników. W przypadku funkcjonującej w ramach konkretnej społeczności biblioteki akademickiej, działalność z zakresu PR musi przystawać do działań całej uczelni. Środowisko uczelniane, tworzące otoczenie biblioteki akademickiej, można określić jako: studentów (również potencjalnych, międzynarodowych, absolwentów), kadrę naukową, władze uczelniane, lokalne, ministerialne, a także inne instytucje non-profit.

Współcześnie trudno sobie wyobrazić bibliotekę naukową nieposiadającą strony internetowej. Serwis www biblioteki traktowany jest przez użytkowników jako oczekiwana i wymagana usługa, która w sposób oczywisty powinna być oferowana przez bibliotekę akademicką. Jednak usługa ta, jeśli będzie nieodpowiednio zlokalizowana, źle organizowana i zarządzana - nie zadowoli klientów, zaś jej działalność może przynieść więcej strat niż pożytku. Zatem istotne jest to, czy biblioteka oferuje wystarczająco wysoką jakość swoich usług.

Dostęp do serwisów, jakość i profesjonalizm ich wykonania warunkują właściwe działania $w$ ramach $\mathrm{PR}$, co w efekcie wpływa na pozytywny wizerunek biblioteki. Zarządzanie serwisem to zagadnienie wieloaspektowe

${ }^{1}$ Jaskowska M.: Public Relations bibliotek naukowych w Internecie. Kraków 2007, s. 19. 
i złożone. Nie zaleca się ograniczania się tylko do jednego obszaru, lecz raczej zadbanie o jak największą liczbę rozwiązań. Współczesne podejście do zagadnienia jakości wymaga postawienia w centrum uwagi klienta. To jego subiektywne odczucia, poziom zaspokojenia potrzeb czy satysfakcja warunkują jakość serwisu www.

Wśród najczęściej wymienianych funkcjonalnych cech serwisów wymienia się:

- Dostęp do serwisu - szybki i prosty dostęp do strony jest warunkiem wstępnym, umożliwiającym dalsze działania. W tym punkcie najważniejszym aspektem jest możliwość dotarcia i dostępu do strony biblioteki ze strony głównej danej instytucji;

- Nawigacja po serwisie - musi być prowadzona w sposób nieskomplikowany, intuicyjny i skuteczny dla możliwie jak największej liczby użytkowników. Wpływa na to obecność mapy i wyszukiwarki pełnoteksowej oraz rodzaj, liczba i jakość odnośników w men (możliwość powrotu do strony głównej z każdego miejsca, powrotu do strony głównej instytucji nadrzędnej i na górę strony).

- Aktualność - strona powinna być na bieżąco aktualizowana, a czas zamieszczania na niej komunikatów jak najkrótszy; warto także zamieścić informacje o dacie ostatniej aktualizacji strony.

- Wiarygodność - serwis powinien być prowadzony przez osoby kompetentne, zarówno jeśli chodzi o wygląd jak i o treści zamieszczane na stronie. Co więcej, użytkownicy bezwzględnie powinni mieć dostęp do danych o tym, kto jest odpowiedzialny za serwis.

- Wielojęzyczność - biblioteki akademickie, ze względu na swój charakter, powinny udostępniać stronę biblioteki także w wersjach obcojęzycznych i to na wszystkich poziomach, nie ograniczając się tylko do strony głównej. Warto zaznaczyć, że o ile około $70 \%$ bibliotek posiada wersję anglojęzyczną serwisu, to inne wersje językowe występują sporadycznie (zależy to głównie od regionu).

- Identyfikacja wizualna serwisu - opiera się ona na konsekwentnych stosowaniu kolorów, symboli firmowych i liternictwa w całym serwisie.

Nie ulega wątpliwości, że własny serwis internetowy jest wizytówką każdej instytucji. Wykorzystując go do promowania instytucji, warto rozważyć, czy chodzi nam o komunikację jednostronną, dwustronną, czy będziemy skupiać się na narzędziach Web 2.0, czy też środek ciężkości ustawimy na komunikacji w trybie rzeczywistym, czy będziemy przekazywać treści podstawowe czy też bieżące komunikaty. Rozpatrując serwis jako narzędzie PR, bierze się po uwagę przede wszystkim: 
- zawartość strony internetowej z punktu widzenia dostarczania informacji (komunikacja jednostronna);

- elementy strony internetowej, ułatwiające interakcję między biblioteką i jej publicznością (komunikacja dwustronna) ${ }^{2}$.

Oczywiście ważne są wszystkie elementy związane $\mathrm{z}$ architekturą informacji, a więc systemy nawigacji, etykietowania, głębokość struktury serwisu, widoczność logo, intuicyjność poruszania się po serwisie, dobór kolorów, czcionek itd. Wszystko to warunkuje odbiór strony www przez użytkownika. Obraz, który zostaje w jego pamięci, powinien być na tyle spójny, by tworzył całość $\mathrm{z}$ istniejącym $\mathrm{w}$ rzeczywistości wizerunkiem biblioteki, lecz na tyle charakterystyczny, żeby wyróżniał się na tle innych, podobnych instytucji.

$\mathrm{W}$ literaturze ${ }^{3}$ wskazuje się na kilka podstawowych zasad, których zastosowanie w praktyce sprawi, że strona biblioteki stanie się przyjazna użytkownikowi. Są to :

1. Konsekwentne stosowanie elementów graficznych - związane jest to z budowaniem systemu jednolitej identyfikacji wizualnej instytucji

2. Link do strony biblioteki powinien prowadzić bezpośrednio ze strony instytucji macierzystej, np. uczelni wyższej - podnosi to wiarygodność serwisu

3. Przejrzysta nawigacja globalna

4. Bazowanie na jednym lub tylko kilku kolorach i małej ilości elementów graficznych

5. Urozmaicenie w sposobie prezentowania zasobów

6. Zminimalizowanie liczby kliknięć, które musi wykonać użytkownik; warto zastosować tzw. szybkie linki

7. Objaśnienie detali na stronie ułatwi użytkownikom dostęp do zasobów ${ }^{4}$.

Obecnie prawie wszystkie czynności codzienne można wykonać wirtualnie - zrobić zakupy, zapłacić rachunki, przejrzeć witryny sklepowe. W związku z tym użytkownicy biblioteki mają w stosunku do niej coraz większe wymagania - dlatego tak ważne jest dobre, planowane zarządzanie serwisem. W Internecie biblioteki konkurują z mnóstwem innych, ciekawych zaso-

\footnotetext{
${ }^{2}$ Jaskowska M.: Public Relations (online) polskich wydawnictw akademickich. Kraków 2004, s. 71.

${ }^{3}$ DeTienne K.: Komunikacja elektroniczna. Warszawa: ABC a Wolters Kluwer Business : International Publishing Service Wydawnictwo, 2009, s. 84.

${ }^{4}$ Jasek C.: How to design library web sites to maximize usability. San Diego: Elsevier, 2004.
} 
bów. Strona www biblioteki akademickiej jest jej narzędziem PR, wobec tego należy mieć świadomość, że dbałość o nią przyczynia się do budowania obrazu całej instytucji.

Na koniec warto zasygnalizować istnienie dwóch niebezpiecznych tendencji we współczesnych PR bibliotek, wykorzystujących narzędzia elektroniczne do promowania swojej działalności. Jako pierwszą z nich można wyróżnić nadmierną fascynację mediami elektronicznymi, bez faktycznego zastanowienia się, czy dane narzędzie rzeczywiście spełni swoją rolę w tej konkretnej bibliotece. Nie powinniśmy udostępniać możliwości porozmawiania z bibliotekarzem za pośrednictwem komunikatora Gadu-Gadu, jeśli nie mamy pracownika, który byłby w stanie na bieżąco odpowiadać na pytania użytkowników. Trzeba pamiętać, że funkcjonalność nie zawsze idzie w parze z użytecznością. Drugą rzeczą, na którą warto zwrócić uwagę jest skłonność do przypisywania technologii nadmiernej roli i złudne myślenie, że medium elektroniczne może zastapić bibliotekarza w pośredniczeniu pomiędzy użytkownikiem a zasobem informacyjnym. Owszem, wykorzystywanie strony www do promocji instytucji jest bardzo potrzebne i pożądane, ale nie można przy tym umniejszać roli kontaktów interpersonalnych, od których jednak powinno się zaczynać planowanie strategii komunikacyjnej biblioteki. Jej wybór powinien wynikać ze świadomej i uzasadnionej decyzji, a nie być podyktowany jedynie wrażeniem o występowaniu jakiejś mody.

\section{Bibliografia}

1. DeTienne K.: Komunikacja elektroniczna. Warszawa: ABC a Wolters Kluwer Business : International Publishing Service Wydawnictwo, 2009. - ISBN 978-8376015-19-4

2. Jasek C.: How to design library Web Sites to maximize usability. San Diego: Elsevier, 2004

3. Jaskowska M.: Public Relations bibliotek naukowych w Internecie. Kraków: Wydaw. Uniwersytetu Jagiellońskiego, 2007. - 978-83-23323-67-9

4. Jaskowska M.: Public Relations (online) polskich wydawnictw akademickich. W: Public Relations. Biblioteki, wydawnictwa, informacja naukowa, uczelnie. Pod red. Marii Kocójowej. Kraków: Wydaw. Uniwersytetu Jagiellońskiego, 2004, s. $68-78$

5. Korycińska-Huras A.: Nowe media w działalności public relations bibliotek. [W:] Public Relations. Biblioteki, wydawnictwa, informacja naukowa, uczelnie. Pod red. Marii Kocójowej Kraków: Wydaw. Uniwersytetu Jagiellońskiego, 2004, s. $158-162$ 